\title{
Belonging in Thuis and 7de Laan: a critical whiteness studies perspective
}

\section{Hannelie Marx Knoetze}

Hannelie Marx Knoetze is a senior lecturer in the Faculty of Humanities, Department of Communication Science at the University of South Africa.

Email: Marxh1@unisa.ac.za

DOI 10.17159/2309-9070/tvl.v.55i2.1885

\section{Belonging in Thuis and 7de Laan: a critical whiteness studies perspective}

Within both the South African and Belgian contexts whiteness manifests as one aspect of national identity and remains (to differing degrees) a normative construction. This article presents the findings of a controlled case comparison of a sample from two community soap operas, 7de Laan and Thuis, broadcast by the South African (SABC) and Flemish (VRT) Public Service Broadcasters respectively, from the perspective of critical whiteness studies. I contend that whiteness functions as an organising principle in the narratives of both soap operas. The goal of this comparative analysis was an investigation into the ways in which whiteness is constructed and positioned in these texts and the implications this has for the politics of belonging. Despite several similarities between the two contexts, they differ significantly, and this created an opportunity to highlight both the consistencies and particularities in the ideological patterning of representations of whiteness, across seemingly unrelated domains, to illustrate its pervasiveness. Notwithstanding their disparate origins, the analysis revealed three rhetorical devices which function to maintain whiteness as hegemonic ideology in both texts. Keywords: 7de Laan, critical whiteness studies, community soap opera. controlled case comparison, politics of belonging, Thuis, whiteness.

\section{Introduction}

In the context of the post-apartheid landscape, where all South Africans are muddling their way into a "complex, nuanced, inherently different future" (Everatt 6-8), Ndebele (46-7) writes that the quest for a new white humanity will only begin to "emerge from a voluntary engagement by those caught in the culture of whiteness of their own making". This article presents one such attempt at voluntary engagement.

There are various ways in which to engage the everyday spaces of the culture of whiteness. Hall (293), for example, posits that one can learn about a specific culture by analysing the stories told by and about this culture since identities are contained in stories told about nations. One possible way of investigating discursive strategies that position and produce whiteness may, therefore, be to look at media narratives and the ways in which whiteness, and belonging, are constructed in these stories. milton ("The televised public sphere: Afrikaans television's role in identity formation" 5-6) writes that in a society as driven towards change as South Africa, it is important that the media be analysed as institutions that could contribute to "national (and transnational) processes of political liberalization and democratization, as potential 
agents of national solidarity, cultural convergence, and social transformation". It is my contention that media narratives could, therefore, also be analysed fruitfully with the goal of engaging whiteness.

In the popular media there is a plethora of available stories one could analyse to this end. For the purposes of this article, I chose to look at soap operas as a source of the stories to which Hall (293) refers. Soap operas often form a substantial part of local productions in a specific country and, as such, become possible contributors to identity formation and perpetuation of dominant ideologies.

This article unfolds as follows: I start out by briefly unpacking the theoretical framework within which the research is situated. This is followed by a substantiation of the choice to focus on two texts in particular and my methodological approach. Finally, I present a textual-visual analysis and comparison of 7de Laan and Thuis and a discussion of the three rhetorical devices perpetuating whiteness which emerged from the analysis.

Within the larger theoretical framework of cultural studies, my specific theoretical approach was critical whiteness studies, a discipline working to "destabilize the assumptions behind whiteness as a cultural norm" (Foster 1). Matthews (9), among others, refers to critical whiteness studies as a possible tool in changing the subjectivities which lie at the heart of white ignorance, an ignorance defined by Steyn ("The ignorance contract: recollections of apartheid childhoods and the construction of epistemologies of ignorance" 13) as "learning what not to know" and "what not to notice". According to her, "[f]or dominant groups especially, it is not as much about accuracy as about how they would like the world to be, and having the power and resources to impose their desires, drives and will upon the social field and to effect social control, that is, to institute an ignorance contract" (Steyn, "Ignorance" 21).

Scholarship in the field of critical whiteness studies provides a site for the radical critique of the racial order and specifically the social positioning of whites as relative to its Others (Steyn, "Postcolonial moment" 420). Alley-Young (309) contends that the goals of this theoretical approach "range from disowning or rejecting whiteness to making it visible in everyday life so that privilege can be catalogued, undone, unlearned, and/or stopped" and this is also the goal of my analysis. According to De Kock (18), critical whiteness studies in South Africa conveys a "sense of urgency of bringing 'whiteness' into visibility as an unreconstructed zone in post-anti-apartheid South Africa". ${ }^{1}$

Three general "waves" of critical whiteness studies can be identified, the most recent of which analyses "diverse cultural sites, including newspapers, autobiographical writings, music, public policy debates, social relationships", etc. (Twine and Gallagher 15) with the goal of exposing whiteness and "decolonising the imagination of both the oppressed and the oppressors" (Steyn, "Postcolonial moment" 421). The topic of this article falls into this category because it interrogates the representation 
of whiteness as the norm in a sample from mainstream public media.

Focusing on soap operas, with specific reference to their ideological and political power, is a contested point of departure. Some critics argue that serious television, such as news and documentaries, is more politicised. However, the critical approach advocated by the Centre for Contemporary Cultural Studies in Birmingham implies that popular texts, such as soap operas, still yield political power. In line with this approach, Barnard (39) argues that "popular culture, alongside political and social institutions [...] chronicle[s] the transformation of the country as well as imaginatively/materially creating a new South Africa". In the same vein, milton ("Local is lekker': nation, narration and the SABC's Afrikaans programmes" 255) contends that popular media provides "privileged access to the social realities of their era" and can thus be read to gain insight into what is actually going on in a society at a given moment. Franco (450), moreover, writes: "Soap opera, the world's most popular form of television drama, has revealed itself to be a productive area of study for cultural significance due to the genre's unique potential to combine local appeal and universal characteristics, exemplified by serial narrative structure, with cultural specificity".

Even though soap operas are often described as "exaggerated, far-fetched, stretching things, over the top, overboard, extreme, even ridiculous or surreal" (Lamuedra and $\mathrm{O}^{\prime}$ Donnell 63) there is widespread agreement that some soap operas are realistic in other respects, such as the way in which they work social issues into narratives. This can be related to La Pastina and Straubhaar's (274) notion of "cultural proximity" soap operas incorporate elements that are familiar to its viewers, and in this way, are perceived as "realistic". Beck (152), moreover, argues that viewers of soap opera are exceptionally vested in the genre and that this leads to "complex, co-constructed narrative intersections that contribute to powerful and multi-layered experiences".

These characteristics of the soap opera thus create rich texts for a study on how whiteness is presented in mass media narratives. The world presented in the soap opera functions as a parallel universe and can be seen as a source of vicarious experiences. Gledhill (360) claims that soap operas are popular due to their "verisimilitude" which she defines as referring "not to what may or may not actually be the case but rather to what the dominant culture believes to be the case, to what is generally accepted as credible, suitable, proper".

Community soap operas, in particular, lend themselves ideally to an analysis of imagined communities within a given context. Due to the local storylines, instances of cultural proximity and presence of "banal nationalism" (Billig), representations in these soap operas can be taken as revealing something about the societies that produce them, while simultaneously providing these societies with ideas on social life and the terms that govern it (Pitout 175). My focus is thus on local soap operas and how these soap operas perpetuate ideologies of whiteness.

The particular characteristic of South African whiteness as having one foot in 
Africa and the other in Europe, moreover, guided me in my decision to do a comparative analysis of a South African and a European, specifically Flemish, soap opera. In relation to power and belonging, this article posits that whiteness functions as an organising principle in the narratives and nature of the imagined communities constructed in two soap operas, 7 de Laan (broadcast by the South African Public Service Broadcaster, the SABC) and Thuis (from the Belgian PSB, VRT) and sought to look at how and why this might be the case.

Despite the disparate origin of the two soap operas there were a number of reasons for the choice to compare them.

Most importantly, considering the purpose of this article, whiteness manifests in both the South African and Flemish contexts as one aspect of national identity, and remains (to differing degrees) a normative construction. In post-apartheid South Africa, for example, identities are destabilised and white South Africans, like the rest, have to reconceptualise how they fit into the broader South African community. Due to apartheid, whiteness and the connotations inherent to the construct remain contentious issues and race discourses are pertinent to the politics of belonging. ${ }^{2}$ In Flanders, discourses of whiteness are less explicit and-like much of Europe-it has no explicit "race" discourse (Costera Meijer and De Bruin 696). Whiteness remains implicitly prevalent, however, especially in the "us" versus "them" dichotomy created by the tension between what Vanhaesebrouck (466) calls a "pristine Flemish cultural identity" and the inherent diversity of the Flemish nation. The "allochton"/"autochton" distinction, moreover, uses language to create binary oppositions which are, to a certain extent, fuelled by latent racism resulting in a "white" versus "other" dichotomy. ${ }^{3}$ Hence this discourse, in all but name, remains a racial one.

Secondly, only soap operas created and distributed for and by the public broadcaster of each particular region were included. Challenges in dealing with diversity have, in both the South African and Flemish contexts, led to a restructuring of PSB mandates on representation and diversity policies. In both cases, the resultant production policies put pressure on texts produced for Public Service Television to be more representative of diversity. In South Africa, for example, the Broadcasting Act of 2002 explicitly outlines its nation building project and the VRT has similar policies meant to guide the representation of the nation on Flemish television (Marx Knoetze and Dhoest 275). ${ }^{4}$ Specifically in relation to soap operas, Franco (452) argues that it seems as though the public service has discovered the potential of soap opera in terms of nation and image building. The fact that PSB programmes in both contexts are mandated to reflect the societies in which they are produced, and the fact that both soap operas claim to do so, made both texts relevant for my analysis. ${ }^{5}$ Due to these mandates it is pertinent to interrogate these soap operas' constructions of the nation, also as it pertains to whiteness.

Another contributing factor was language. 7de Laan's predominant use of Afri- 
kaans is significant since Afrikaans as a language is intimately connected to whiteness. Even though white South Africans are not the only mother-tongue speakers of Afrikaans, in the early 1900s it was re-conceptualised as a "white man's language". 6 The language is, furthermore, politically and ideologically connected to whiteness owing to apartheid and its concomitant language policies-hence the reference to Afrikaans as the "language of the oppressor". Moreover, since the Afrikaans debate is often driven by white Afrikaner cultural organisations, there is a tendency to confuse Afrikaans as "belonging to" white Afrikaners. ${ }^{7}$ Considering the goal of this article, the Afrikaans soap opera was the obvious choice. Moreover, the palpable link between Afrikaans and Flemish situates the two soap operas favourably in terms of comparison. ${ }^{8}$

In addition to the similarities mentioned above, both soap operas can be classified as community soap operas (as defined by Liebes and Livingstone 153). Finally, both texts can be classified as successful since they have been on the air for more than a decade and consistently score some of the highest audience ratings in their particular contexts. ${ }^{9}$

The methodological paradigm applicable to this project is qualitative and the method is a textual-visual, controlled case comparison of purposive samples from 7 de Laan and Thuis. A comparative analysis provides the opportunity to look beyond the usual national framework applied to context-specific research. It denaturalises the media and reduces the risk of assuming certain aspects of media representations to be "natural" (Hallin and Mancini 2). I conducted a comparison of how the settings and communities, language use and representation of diversity in the two soap operas construct the imagined communities of each context by analysing six months' worth of episodes from season 17 of Thuis (broadcast from January to May 2012), and a similar sample of 7 de Laan episodes (broadcast from January to May 2013). Comparing a soap opera from an established media economy to one from an emerging media economy afforded me an opportunity to highlight the consistencies in the ideological patterning of representations of whiteness, across seemingly unrelated domains, to illustrate its pervasiveness.

\section{Imagined/image communities: 7de Laan and Thuis}

At the time of writing, 7de Laan, aired on SABC 2, was the most popular South African, Afrikaans, soap opera (SAARF2014). ${ }^{10}$ Thuis, a Flemish soap opera that is broadcast daily on the Flemish public service television channel Eén (One), is the longest-running television programme on Flemish television.

The imagined communities depicted in these popular soap operas are close-knit and consist of ordinary characters from different generations living together in harmonious neighbourhoods. Although 7de Laan's setting is more urban (owing to its connotations with Johannesburg), both Hillside and the fictional village in which 
Thuis is set connote small town living, neighbourliness and a focus on the everyday. ${ }^{11}$ These connotations to home and the familiar are supported by the titles of the soap operas, with Thuis literally referring to the home and 7de Laan connoting familiarity because almost every South African town has a $7^{\text {th }}$ Avenue. All of the above, in conjunction with the fictional, yet familiar, nature of both settings as represented through recognisable activities and personae, make it possible for viewers to identify with the inherent "Flemishness" of Thuis or a utopian version of the South African rainbow nation ideal in 7 de Laan.

All the action is centralised in these unified, closed communities and all the characters are depicted as sharing similar ideals related to conservative middle-class values and the nuclear family. Characters participate in the same cultural practices and rarely venture outside the closed space of the community. Examples of these cultural practices in the available sample include Bingo and wine tasting in $7 d e$ Laan and searching for hidden coins in the "Driekoningen taart" (Three kings' tart) in Thuis. Cultural practices perceived as being outside of the homogeneous culture are marked as different. In 7de Laan, Hilda's "Ikebana" classes are a case in point. Oubaas describes the practice of Ikebana as "volksvreemd" (foreign), thus explicitly rejecting a practice he perceives to be foreign to his "volk" (people).

While closed settings are congenital to soap operas, in this case these settings are used as rhetorical devices which create a visual metaphor for the normative behaviour outlined above. These normative constructions can be read as presenting a specific take on the politics of belonging within the represented South African and Flemish communities. Hence belonging to the imagined community of 7 de Laan or Thuis requires the practice of normative behaviour, represented as the utopian ideal for the societies these soaps depict.

Favell defines the politics of belonging as the "dirty work of boundary maintenance" (Yuval-Davis 3), and Chidester (163) refers to representations such as the above as a "boundary under patrol". In both cases the invisible boundary of the utopian soap opera setting protects insiders against any perceived threats to their physical solidarity and cultural unity. These closed settings create a sense of purity and internal homogeneity which is cosseted against outsiders by regulating contact with anyone perceived as Other, thus affording insiders the opportunity to deflect any guilt about societal wrongs.

An example of the patrolled boundaries in these texts is the conversion of public spaces to private ones. Oppikoffie (a local coffee shop featured in 7de Laan) or the Zus and Zo (a restaurant and guesthouse in Thuis), for example, are both public places, which also function as settings in which the private lives of the characters play out and within which mainly characters from the casts interact. These public, yet private, spaces contribute to the creation of a boundary between the soap opera world and the world "out there", minimising the danger of interaction with the Other, even in public spaces. 
When it is not possible to deflect guilt or difference on to an outsider, Otherness is created internally in the form of the "bad white body" (Foster 137). The eternal "super-bitch" is one such example. Gita McGregor, in 7de Laan, is an example par excellence of the evil female protagonist. She is the bad character against which all other characters' goodness can be opposed. ${ }^{12}$ Nancy in Thuis, is another example of how not to behave. Her vulgar and inappropriate behaviour constructs her as marginal "white trash" and functions as confirmation of the centrality of "normal whiteness". Neither character, however, is depicted as absolutely bad. Both are represented as three-dimensional characters where their good characteristics are also highlighted, ensuring their access to the in-group. The possibility of reform and re-integration into the utopian ideal is always imminent, and the homogeneous equilibrium is therefore constantly restored.

This homogeneous construction of both imagined communities displays the characteristics which Foster (30) links to whiteness as a location of structural advantage. Foster (23) identifies heteroperformativity, homogeneity, bravery, the nuclear family, rationality, class and civilisation as characteristics or discourses of whiteness. By this logic, both communities are depicted as essentially "white". Moreover, seen against the background of what Steyn ("Ignorance") calls the "ignorance contract", it seems that both soap operas present a homogeneous "feel good" community, which enables viewers to continue believing in the viability of such an amended reality and, in so doing, perpetuates ignorance. ${ }^{13}$ Despite the entertainment purposes of these texts, the specific viewpoint from which the imagined communities are constructed allows for a kind of "protective pillow" (DiAngelo 55) insulating whites from facing their position of privilege.

These tendencies are also identifiable in the application of language in the chosen texts. Both Afrikaans and Dutch are particularly salient as markers of identity in their respective contexts. ${ }^{14}$ Consequently, the use and application of both languages in these texts construct the politics of belonging in a specific way.

In Thuis, Flemish Dutch is the uncontested primary language.$^{15} 7 \mathrm{de}$ Laan is multilingual and includes English subtitles, but is broadcast predominantly in Afrikaans. Despite its multilingualism, all the characters in 7de Laan ostensibly accept Afrikaans to be the primary language. While there are some characters, such as Marco and Aggie, who speak English and other African languages, it happens infrequently, and everybody switches to Afrikaans seamlessly and without hesitation when an Afrikaans-speaking person enters the conversation. In conjunction with the construction of the community outlined above, language thus functions as a unifying factor in both texts and contributes to the creation of a homogeneous in-group.

Not only the choice of languages, but also their applications are significant to the politics of belonging and the negotiation of power. Even though both soaps use a standardised version of their primary language, Thuis incorporates different dialects 
as an indication of the class differences of the characters. In 7de Laan, however, the sole use of standard Afrikaans is classified by milton ("Local" 268) as "deterritorialisation" and the lack of intralinguistic diversity ultimately contributes to a homogeneous construction of Afrikaans-speaking South Africans, which is contrary to the actual diversity of its speakers.

The fact that the casts of both soap operas share a primary language might be read, on the one hand, as language fulfilling a transformative and unifying role. Moreover, hosting Afrikaans and Flemish programmes are in line with the language policies of both PSBs. On the other hand, however, particularly in the South African case, it could also be read as a sort of escapism, where one particular language is used free from the guilt of excluding or dominating other languages. ${ }^{16}$

The language choice in the two texts also differs in that, in Thuis, the primary language, Flemish Dutch, is linked to the construction of a subnational identity, while the Afrikaans used in 7de Laan is specific to only two language communities in the country. Although it is not my intention to read prejudice into a text that is specifically created (until recently at least) in Afrikaans, for a predominantly Afrikaans audience, the fact remains that Afrikaans is an ideologically loaded language. ${ }^{17}$ Moreover, concerning the intended target audience of 7 de Laan, producer Danie Odendaal claims that, while the primary language of the soap opera is Afrikaans, it was never intended to be a "white soapie" (Van Zyl and Venter). Odendaal's comments are an indication of 7de Laan's ideological positioning. The connection he makes between Afrikaans and whiteness is telling, since brown people are the predominant speakers of the Afrikaans language in South Africa. ${ }^{18}$ The producer's ideological linking of Afrikaans to whiteness can be read as part of the underlying assumptions governing its production. Read in the context of Odendaal's comments, Afrikaans' history as the "language of the oppressor" and the use of English as the second most prominent language in 7de Laan, one cannot help but notice the underlying white ideology of the text. Thus, the construction of an almost completely Afrikaans community as representative of South Africa remains problematic.

Regarding Thuis, even though the use of Flemish Dutch is in line with the public broadcaster's primary audience, and some degree of regional variation is included, its sole use is indicative of the homogeneous construction of the Flemish nation and the stringent integration policies which oppose the diversity the public broadcaster aims to represent. In both cases, language is used to patrol the boundaries of the closed communities and belonging is constructed linguistically.

In contrast to the above, both soap operas attempt-at first glance-to represent diversity in terms of class, gender and race (or ethnicity). Viewers are presented with a utopian ideal of everyone living together in one community without fear of victimisation, discrimination or prejudice. The South African society is represented as a non-racialised rainbow community and the Flemish society as a homogeneous 
community into which ethnic minorities are successfully integrated. Both soap operas present heteronormative gender and sexual roles as the standard and class differences, although present, are depicted as easily bridged. In line with the characteristics of the genre, both texts present liberating, strong female roles as well as giving the males feminine traits (such as a predilection for talk and emotion).

Characters representative of different social strata are part of each of the communities. Both soap operas are, however, aspirational in the sense that class differences are not presented as problematic to upward mobility. A case in point would be Errol in 7de Laan, a brown orphan, who went from being homeless to becoming an award-winning journalist. Class-related problems are resolved quite effortlessly, perpetuating the homogeneous nature of the community. Despite the relative ease with which class differences can be overcome, as well as the fact that it is never referred to as a race issue, however, it is telling that in 7 de Laan, all the whites are upper or middle class, and only black or brown characters are depicted as coming from a lower class.

Linked to this, during the period of analysis attempts were made in 7 de Laan to depict interracial relationships, but only between brown and white characters (such as Felicity and Herman), never between white and black or brown and black characters. Concerning class, it was mainly brown characters that were presented as upwardly mobile. As far as representing racially specific cultural practices, one traditional black wedding was featured in 7 de Laan a number of years ago. However, when issues such as these were screened, it was always in the form of a "themed" issue, specifically dealing with race matters, and not depicted as part of the everyday life of the community. It is arguable that such "themed" issues emphasise these practices, giving them more prominence, but at the same time these are constructed in such a way that they fall outside of the daily lives of the main characters- $a$ "cultural experience" as it were. During season 17, no such representations were featured in the narratives of Thuis.

Race and matters relating to race or ethnicity fall mostly outside the purview of both soap operas. Even though both soap operas, but 7 de Laan in particular, include characters from various races or ethnicities, the behaviour of these characters is rarely marked as race specific and, consequently, they all display normative behaviour, perpetuating white ideology as "no-Culture" (Frankenberg 204). It is arguable that these homogeneous presentations are created in order to provide an ideal for a selfevidently diverse society, but, in contrast to such an argument, the fact remains that presence is not enough to begin to reflect the actual racial diversity of both societies.

The verbal silence on race-related issues, furthermore, contributes to the construction of internal homogeneity. In Thuis in particular, despite the integration of some ethnic-cultural diversity (for example Lynn, a Moroccan law student with white adoptive parents), race remains largely invisible and definitively unspoken. This 
could be read as a reaction against the critique that ethnic-cultural minorities are mostly represented as tied to their cultural background and the problems associated with it (in, for example, the news). However, as a consequence, cultural diversity is effaced, and the problems related to the co-existence of people with different cultural backgrounds are side-stepped. Even though both texts avoid any explicit claims to race or the centrality of a particular race, their perpetual silence creates fertile ground for whiteness to thrive uncontested as dominant ideology.

A significant difference between the two texts is their levels of engagement with issues of gender diversity. Gender diversity and sexual identities are depicted in more depth in Thuis, as evidenced in, for example, the gay and lesbian couples and their prominent roles in the narrative. This situation mirrors tendencies in society at large since it is arguable that, in Belgium, homosexuality has been incorporated into the norm and LGBT rights have become part of the "national" imagined community. ${ }^{19}$ The level of critical engagement with gender issues is evidenced in the representation of different opinions about Frankie and Tibo's same-sex marriage and the consequent questioning of heterosexual marriage as the norm. In contrast, in $7 \mathrm{de}$ Laan, the only reference within the scope of the analysed period was a stereotypical camp performance (when Diederik was hypnotised and ordered to "act"gay) with the purpose of comic relief, or arguably, ridicule.$^{20}$ In this instance, entertainment was clearly the main goal. While entertainment remains the primary purpose of both texts, the reluctance to address gender-related issues in 7 de Laan is also indicative of the more conservative nature of South African society and, to some extent, this is reminiscent of patriarchal, apartheid society where certain issues were taboo. Croucher (316) writes in this regard that "[s]ame-sex sexualities are foreign to, and inconsistent with, true Afrikaner identity". "Afrikaner" identity, in turn, is linked explicitly to whiteness, and in this way, 7 de Laan enforces heteronormative behaviour as linked to whiteness.

Stokes (191) views heterosexuality and whiteness as normative co-partners in the construction of power. Linked to this, and central to both soap operas, is the prominence of the nuclear family (even as a myth). Despite the crumbling of the family structure in various narratives, the myth of the nuclear family is still propagated as the ideal in both soap operas. Heteronormative performances of marriage and parenthood are also considered to be well-performed whiteness. In both soap operas, such performances are presented as well-performed citizenship and considered the behaviour accepted and promoted by the in-group.

Because difference cannot be completely avoided, some less extreme performances of differences are appropriated into the dominant group. Examples of these appropriations are "acceptable" performances of homosexuality and class or racial difference. Maikey (126) refers to this as "homonationalism", which is defined as "the normalization and integration of certain 'more acceptable' queers into the nationalist 
ideal", a strategy which is relevant in Thuis, but still falls outside the purview of the analysed representations in 7de Laan. Visual racial diversity in 7de Laan, and to a lesser extent in Thuis, is similarly assimilated into the norm. The same applies to class. Class difference is not presented as an enduring threat but rather glossed over or used for comic relief, and consequently tolerated or absorbed into the homogeneous in-group.

Through homogenisation both cases, to a certain extent, mirror national patterns of lack of dealing with issues of difference. While Thuis deals with issues of gender and sexual diversity in a more nuanced way than 7de Laan, the narratives of both soap operas support the construction and maintenance of white hegemony. It is arguable that 7de Laan represents "pro new South Africa" discourses, but these instances offer little more than superficial support and exert no tangible influence on the status quo. Similarly, despite being awarded the "integration prize", the relatively homogeneous nature of the Thuis cast mirrors the general reluctance towards integration in Flanders. Furthermore, the presence of difference alone does not guarantee nuanced depictions, and even the depiction of same-sex relationships in Thuis still runs the risk of reiterating heteronormative values due to their focus on the nuclear family (Dhaenens 443).

The characteristics identified by Foster (23) as linked to whiteness also intersects with other discourses of privilege (such as patriarchy) and these discourses thus mutually reinforce each other. However, whiteness is also known for its constant mutation and evolution. As such, both texts manage to incorporate characters representative of different ethnicities, classes and genders, while still foregrounding homogeneous normative performances portrayed as the ideal behaviour in the soap communities. Thus, whiteness, as a construct, becomes an umbrella term encompassing a range of hegemonic ideologies. Normative representations of sexuality, gender and class all work together to create a homogeneous representation of a closed community epitomising behaviour associated with whiteness.

\section{A wolf in sheep's clothing: homogeneity tinted white?}

This comparative analysis indicates that, despite pressures to be representative, both texts resist or negate these pressures to some extent. Three rhetorical devices emerge from the analysis as central to the maintenance of whiteness as hegemonic ideology. These are: the presence of absence, the boundary under patrol and the construction of the audience as part of the "inner circle".

According to Nakayama and Krizek (in Alley-Young 312) one performative action which functions to hide whiteness and white skin privilege is to speak of whiteness in the negative, or as an absence of race or ethnicity. Chidester's (160) theorisation of the "presence of absence" can be related to this performative action. The absences in the soap operas are as important as the presences, and these absences, or silences, function as vital rhetorical devices in both texts. According to Chidester (160) some 
silences become an intention. In other words, silence becomes rhetorical when it is a conscious choice. If there is an insistence on presence as a carrier of meaning, it follows logically that absence similarly constructs meaning.

Riessman (540) argues that one should take into account any gaps or inconsistencies in a specific narrative which might suggest preferred, alternative or counternarratives. Silence on matters of race and, to some extent, class and gender issues are gaps that contribute to establishing whiteness as a system of dominance in the soap operas under discussion. My argument for the centrality of whiteness in these texts does not rely on essentialist notions of race, but on how other cultural normativities, such as heteronormativity, for example, work together to maintain privilege.

Both texts display absences in terms of the representation of diversity as well as an absence of overt discourses on difference. In Thuis, ethnic minorities, particularly during the analysed period, are not really present on screen, while in 7de Laan the more representative cast does little to address the absence of any real discourse on difference. Giving more prominence to such issues might reveal the inherent whiteness of the text and bring the ideologies and practices presented as normative into visibility. Thus, although different approaches are taken, both result, once more, in the perpetuation of white normativity. Screen presence, in both cases, does not solve the problem of racial and ethnic representativeness. These absences make it possible for one of whiteness's most enduring characteristics, namely ignorance, to thrive, since it merely functions as the uncontested norm. Whiteness is thus not maintained by any overt rhetoric, but rather by its everydayness (Shome 366).

In addition to the rhetorical silence on racial issues, the analysis also brought to light that both texts present a closed setting, which enforces the idea of insiders being insulated against "the world out there" and thus also against heterogeneous outsiders. This is in line with Foster's (23) argument that whiteness and related dominant performances provide a centre against which anybody not belonging to the group can be classified as Other and marginal. Owing to the fact that whiteness's existence is dependent upon its binary opposite, it is fuelled by a fear of hybridity and dependent upon a rejection of such hybridity and an elimination of internal difference. Sleeter (261) suggests that these images of homogeneous in-group bonding, and the metaphor of the closed setting "have the purpose of affirming a common stance on race-related issues, legitimating particular interpretations of oppressed groups, and re-drawing we-they boundaries".

In 7 de Laan, the construction of a homogenous inner circle underpins the ideal of the existence of a society without any significant challenges to the status quo, while Thuis represents an inner circle in which the practices and culture of the majority are taken to be the uncontested norm and which, as elsewhere in Europe, are predominantly, and self-evidently, white. In Thuis, like in Flanders, the imagined community emphasises the integration of ethnic minorities, rather than questioning the 
normative functioning of whiteness. Race or ethnicity is not explicitly referenced, and belonging is constructed along the lines of what is considered to be Western and non-Western. Nakayama and Krizek (293) refer to this communicative strategy as "claiming European origins to avoid claiming whiteness".

However, even though the community is constructed as internally homogeneous, McKee (13-4) rightly states that there is a wide range of images of whiteness as evidenced by the incorporation of accepted gender and class differences in these communities. This multiplicity of articulations of whiteness make it possible for whites to identify, albeit internally, as diverse.

Against the backdrop of this internal homogeneity, "bad" characters are introduced as outsiders and interlopers rarely pose a permanent threat. Such interlopers are usually only present until the denouement of a particular narrative thread and are almost always brought to task, in effect serving the purpose of confirming the efficacy of the moral high ground occupied by the insiders and re-establishing equilibrium.

Even though explicit binaries, such as whiteness versus blackness, are not evoked in the texts, whiteness as the norm defines itself as not bad, evil, irrational or uncivilised. The in-group is defined against the perceived evil of the unseen out-group, and all complicity in discrimination or the perpetuation of difference is located externally. Hence all the homogeneous practices associated with whiteness are depicted as the characteristics of the homogeneous soap opera society, and any deviant behaviour is situated outside of this closed circle. In this way, visual and performed whiteness can function in the closed settings of both soap operas without any significant racial threat, confirming DiAngelo's (55) notion of the protective pillow and Steyn's "ignorance contract" ("Ignorance").

The third rhetorical device that emerged from the analysis is the way in which the audience is constructed as part of the in-group in the soap opera, making it possible for them to also deny any complicity in the perpetuation of discrimination like the characters on screen. Both soap operas create a feeling of verisimilitude and literally function as a setting or background extending from the living rooms of its viewers. Always viewed from the same, familiar vantage points, these sets and characters invite viewers to belong to the 7de Laan community, or to feel "at home" in Thuis, and to identify with the social roles of the characters (Pitout 168). Viewers are able to shift accountability and guilt regarding discriminatory practices existing in society elsewhere in the same way in which their favourite characters project these on to the evil outsider. Even though both texts are presented as colourless or non-racial, both, at least to some extent, perpetuate whiteness. The impact of these normative constructions, absences and boundaries is particularly salient when understood by audiences as a choice, and the fact that these soap operas serve to "reinforce perceptions of whiteness's centrality as a racial subjectivity among some viewers" (Chidester 170) has implications.

Viewers are not encouraged to see 7 de Laan or Thuis as an unrealistic picture 
of contemporary race relations, but rather as "an idyllic setting free of any explicit discourse on race or accusations of racial domination, a safe haven for those viewers most heavily invested in preserving a sense of whiteness as an unspoken marker of privilege" (Chidester 168). Consequently, it is possible for viewers to see both soap operas' homogeneous communities as reflective of their own segregated material experiences as well as of television's highly segregated landscape (Chidester 169).

White, hegemonic, normative perspectives are continuously presented as the logical point of view, negating difference and hybridity, a fear of which lies at the heart of whiteness. As such, both soap operas contribute to "the overall visual/cultural web that continues to enable whiteness' mute, pervasive privilege" (Chidester 170) in both of these societies.

Moreover, both soap operas remain unequivocally popular, which leads me to believe that the popularity and value of these programmes do not only lie in entertainment but, at least in part, in their defence of a certain hegemonic privilege with which the audience associates.

If popular cultural texts provide a symbolic construction based on which viewers can construct their collective identities, the homogeneous treatment of the image/ imagined communities in both soap operas is problematic. The three rhetorical devices identified here illustrate a tendency for these texts to construct a particular view of society where the nature of the closed society with all the "absences" and all that is left unsaid make it possible for whiteness to thrive, but also to adjust fluidly to changing circumstances without any immediate threats. Whiteness is presented in these texts as something "that is invisible, working in the background as a standard, not of one particular way of being in the world, but as normalcy, as universalizability, of just 'being the way things are'" (Vice 324), a sort of banal perpetuation of the dominant ideology. Despite the fact that both texts attempt to represent a version of diversity, they both perpetuate its opposite, namely sameness, presenting the viewer with homogeneity tinted white.

\section{Conclusion}

This controlled case comparison sheds some light on the way in which whiteness functions as a hegemonic ideology in a sample of mass media products, even across diverse settings.

Owing to its elusive nature, I cannot claim the absolute dominance of whiteness in the soap operas I analysed. Essed and Trienekens (54), however, remind us that the "critical studies of whiteness are more about cultural normativities, political appropriations and social-economic practices, privileging whites compared to other populations". Thus, exactly because whiteness is not about essentialist notions and its maintenance is a process involving various material and social practices, I argue that, when viewed as a whole, the practices, spaces and identity constructions in 
both texts are perpetuating whiteness and the ideologies associated with it.

These homogenous imagined communities are problematic, because the creation of such unity and homogeneity always implies the exclusion of difference and as such have important implications for the politics of belonging as they play out in these texts. The result is a type of forced homogeneity which glosses over the underlying differences in both nations and reinforces dominant ideologies of whiteness.

The number of similarities and overlaps between the way whiteness is perpetuated in the South African and Flemish context is important precisely because of the way in which the contexts differ. The similarities between the two case studies seem to indicate that the normative representation of whiteness is not something that is exclusive to popular culture in either the global South or the global North. These similar manifestations speak to whiteness's power of endurance, but also point to its constant evolution, to the nature of whiteness as a process, rather than an absolute entity. According to Bailey (40), white people can only develop anti-racist identities if they "get out of those locations and texts where they feel at home [...] [and] put [their] privileged identities at risk by travelling to worlds where [they] often feel ill at ease and off-center (sic)". Risking these privileged identities is an opportunity sadly not presented by either of these texts.

\section{Acknowledgements}

This paper is based on the PhD dissertation, "South African and Flemish soap opera: a critical whiteness studies perspective", completed at the University of South Africa, Pretoria, in 2015. The supervisors were v. c. milton, P. J. Fourie (Unisa) and A. Dhoest (Antwerpen).

\section{Notes}

1. Even though there are individual researchers referring or contributing to critical whiteness studies, there is no identifiable body of work which may constitute Belgian/Dutch whiteness studies as a theoretical field.

2. Yuval-Davis (5) writes that the "politics of belonging comprise of specific political projects aimed at constructing belonging to particular collectivities which are themselves being constructed in these projects in very specific ways and in very specific boundaries".

3. Central to the discourse on Flemish identity is the struggle to accurately name non-EU migrants. From the 1990s, the term allochtoon (literally translated as "from another country"), as taken from the Netherlands, came into use to describe second- and third-generation ethnic minorities (Marx Knoetze \& Dhoest 272). Allochtoon is opposed to autochtoon (Belgian). These descriptive concepts "set apart 'US' from 'THEM'; the real Dutch (autochtoon) from the not-quite-Dutch (allochtoon)" (Essed and Trienekens 57).

4. The scope of this article does not allow for in depth attention to the respective contexts and histories of each country. For a detailed comparison please refer to Marx Knoetze and Dhoest ("Negotiating national unity and diversity in public broadcasting: A comparative study on South Africa and Flanders.").

5. In contrast to this, texts created for the pay-to-view or commercial channels in South Africa and Flanders are not required to adhere to the same stringent specifications which make it more challenging to pinpoint their stances on the representation of diversity. 
6. In 1905, for example, journalist Gustav Preller "set about reinventing Afrikaans as a 'white man's language'". He aimed to eradicate the stigma of its "coloured ties by substituting Dutch words for those with non-European origins" (Anon.).

7. When speaking of the "Afrikaans debate" I am referring to the debate about Afrikaans on South African television.

8. Afrikaans is a daughter language of Dutch and an estimated $90 \%$ of its vocabulary has a Dutch origin. It originated around 1685 and was colloquially referred to as "Kitchen Dutch". There is a large degree of mutual intelligibility between Dutch and Afrikaans, particularly in the written form.

9. Thuis was launched on 23 December 1995. It is aired on weekdays and continues to be one of the most popular local television programmes in Flanders. Similarly, 7de Laan aired its first episode in April 2000 and it remains one of South Africa's most popular locally produced soap operas.

10. The fact that 7 de Laan is broadcast on SABC 2, with its tagline, You belong, implies that it caters for an audience primarily falling into the LSM group 5-7 and mostly speakers of Sotho, Afrikaans, Venda, Tsonga and English. Although 7de Laan is an Afrikaans soap opera and was commissioned for the upper-income category, it has a much wider audience base (Van der Merwe 36). The audience demographics of the soap opera seem to be spread almost equally between white (33\%), brown (35\%) and black $(31 \%)$ viewers; the remaining $1 \%$ constitutes Indian viewers.

11. As South Africa's largest city, Johannesburg, also colloquially referred to as "Jozi" or "eGoli" (City of Gold) is the epitome of South African corporate success and urban living, often described as "Africa's economic power house". It is home to a vibrant and diverse community of South Africans, but is also considered to be one of the most dangerous cities in the world.

12. Gita is also one of the only English-speaking characters in 7de Laan, which adds another dimension to her "bad whiteness" and distances her from the Afrikaans-speaking "good whites".

13. Steyn ("Ignorance" 22) contends that at the heart of societies structured in racial hierarchies (such as South Africa and, to some extent, Flanders), lies an "ignorance contract" described as a "tacit agreement to entertain ignorance". It is her contention that the process of ignorance-making which was prevalent during apartheid continues in post-apartheid South Africa.

14. In the South African context, Afrikaans is the mother tongue of two distinct language communities, namely the white, Afrikaans-speaking community, on the one hand, and a large, brown, Afrikaansspeaking community, on the other. Its main connotations, however, are of being the language of apartheid and the (white) oppressor. When taking into consideration its negative connections to Afrikaner nationalism, as well as the highly polarised nature of South African society, it is clear that Afrikaans plays an ambivalent, but important, role in the South African nation-building project. In the Flemish context, Belgian Dutch is a vital indicator of belonging to Flemish society, in particular, in distinguishing Flemings from the broader Belgian society and Wallonia, the French-speaking part of Belgium. Moreover, Belgian Dutch is one of the seminal requirements for integration into the Flemish community, a marker for the degree to which ethnic minorities are integrated into "Flemishness".

15. According to Geeraerts (2), Belgian and Netherlandic Dutch are examples of what is referred to in contemporary linguistics as "national varieties of a given language". For the purposes of this article, the language spoken in Flanders will be referred to as Belgian Dutch/Flemish Dutch" (Franco 455).

16. These problems, specifically with regard to 7 de Laan's application of language, are reflected in the fact that it has come under the scrutiny of the public broadcaster. This resulted in a change in the soap opera's language policy, slightly reducing the use of Afrikaans in the spoken dialogue.

17. As part of the larger project to give the soap opera "new life", at the time of writing this article, the $\mathrm{SABC}$ mandated that the text of 7 de Laan be written in English and then translated into Afrikaans (Swanepoel 35).

18. For the purposes of this article I use the term "brown" when referring to that part of the population classified by the apartheid government (but still applied as a classification system today) as "coloured".

19. This could, however, also be viewed as homonationalism at work.

20. It should be noted here that in March of 20177 de Laan aired its first gay kiss (albeit as part of a sub-plot). This might be viewed as progress, but it is also arguable that it is very little, very late considering that other major soap operas such as Isidingo, Rhythm City and Generations have long ago started portraying gender diversity. 


\section{Works Cited}

Anon. "The history of Afrikaans." n. d. roughguides.com/destinations/africa/south-africa/the-history-ofafrikaans/. Accessed 11 Nov. 2015.

Alley-Young, G. "Articulating identity: refining postcolonial and whiteness perspectives on race within communication studies." The Review of Communication vol. 8, no. 3, pp. 307-21. DOI: https://doi. org/10.1080/15358590701845311.

Bailey, A. "Locating traitorous identities: toward a view of privilege-cognizant white character." Hypatia vol. 13, no. 3, 1998, pp. 27-42.

Barnard, I. "The language of multiculturalism in South African soaps and sitcoms." Journal of Multicultural Discourses vol 1, no. 1, 2006, pp. 39-59.

Beck, C. S. "Intersecting narratives: enjoying daytime drama as viewers (and actors) experience the days of their lives." Communication Studies vol. 62, no. 2, 2012, pp. 152-71. DOI: https://doi.org/10.1080/10 510974.2011.638413.

Billig, M. Banal Nationalism. London: Sage, 1995.

Chidester, P. "May the circle stay unbroken: friends, the presence of absence, and the rhetorical reinforcement of whiteness." Critical Studies in Media Communication vol. 25, no. 2, 2008, pp. 157-74.

Costera Meijer, I and J. de Bruin. "The value of entertainment for multicultural society: a comparative approach towards 'white' and 'black' soap opera talk." Media, Culture and Society vol. 25, 2003, pp. 695-703.

Croucher, S. "South Africa's democratisation and the politics of gay liberation." Journal of Southern African Studies vol. 28, no. 2, 2002, pp. 315-30.

De Kock, Leon. "The call of the wild: speculations on a white counterlife in South Africa." English in Africa vol. 37, no. 1, 2010, pp. 15-39. www.jstor.org/stable/27807128.

Dhaenens, F. "Queer cuttings on YouTube: re-editing soap operas as a form of fan-produced queer resistance." European Journal of Cultural Studies vol. 15, no. 4, 2011, pp. 442-56. DOI: https://doi. org/10.1177/1367549412442205.

DiAngelo, R. "White fragility." International Journal of Critical Pedagogy vol. 3, no. 3, 2011, pp. 54-70. http:// libjournal.uncg.edu/ijcp/article/view/249.

Essed, P. and S. Trienekens. "Who wants to feel white? Race, Dutch culture and contested identities." Ethnic and Racial Studies vol. 31, no. 1, 2008, pp. 52-72.

Everatt, D. “Non-racialism in South Africa: status and prospects." Politikon: South African Journal of Political Studies vol. 39, no.1, 2012, pp. 5-28. DOI: https://doi.org/10.1080/02589346.2012.656910.

Foster, G. A. Performing Whiteness: Postmodern Reconstructions in the Cinema. State U of New York P, 2003.

Franco, J. "Cultural identity in the community soap: a comparative analysis of Thuis (At home) and EastEnders." European Journal of Cultural Studies vol. 4, no. 4, 2001, pp. 449-72. DOI: https://doi. org/10.1177/136754940100400405.

Frankenberg, R. The Social Construction of Whiteness: White Women, Race Matters. U of Minnesota P, 1993.

Geeraerts, D. "Every language in the media: the case of Belgian Dutch soap series." Sprache im alltag. Beiträge zu neuen perspektiven in der linguistic Herbert Ernst Wiegand zum 65. Eds. M. Kammerer et al. Walter de Gruyter, 2001, pp. 281-91.

Gledhill, C. "Genre and gender: the case of soap opera." Representation: Cultural Representations and Signifying Practices. Ed. S. Hall. London: Sage, 2003, pp. 337-86.

Hall, Stuart. "The question of cultural identity." Modernity and its Futures. Eds. S. Hall, D. Held and T. McGrew. Polity, 1992. pp. 273-326.

Hallin, D. and P. Mancini. Comparing Media Systems: Three Models of Media and Politics. Cambridge U P, 2004.

Lamuedra, M. and H. O'Donnell. "Community as context: EastEnders, public service and neoliberal ideology." European Journal of Cultural Studies vol. 16, no. 1, 2012, pp. 58-76. DOI: https://doi. org/10.1177/1367549412457479.

La Pastina, A. C. and J. D. Straubhaar. "Multiple proximities between television genres and audiences: the schism between telenovelas' global distribution and local consumption." The International Journal for Communication Studies vol. 67, no. 3, 2005, pp. 271-88. DOI: https://doi.org/10.1177/0016549205052231.

Liebes, T. and S. Livingstone. "European soap operas: the diversification of a genre." European Journal of Communication vol. 13, no. 2, 1998, pp. 147-80.

Maikey, H. "The history and contemporary state of Palestinian sexual liberation Struggle." Ed. A. Lim. The Case for Sanctions against Israel. Verso, 2012. pp. 121-30. 
Marx Knoetze, H. and A. Dhoest. "Negotiating national unity and diversity in public broadcasting: A comparative study on South Africa and Flanders." Catalan Journal of Communication \& Cultural Studies vol. 8, no. 2, 2016, pp. 265-81.

Matthews, S. "Becoming African: debating post-apartheid white South African Identities." African Identities vol. 9, no. 1, 2011, pp. 1-17. DOI: https://doi.org/10.1080/14725843.2011.530440.

McKee, P. Producing Races: Henry James, William Faulkner, Toni Morrison. Duke U P, 1999.

milton, v. c. "The televised public sphere: Afrikaans television's role in identity formation." NRF project brief, 2006.

. "Local is lekker': nation, narration and the SABC's Afrikaans programmes." Communicatio vol. 34, no. 2, 2008, pp. 255-77. DOI: https://doi.org/10.1080/02500160802456197.

Nakayama, T. L. and R. L. Krizek. "Whiteness: a strategic rhetoric." Quarterly Journal of Speech vol. 81, 1995, pp. 291-309.

Ndebele, N. “Iph'indlela? Finding your way into the future." Social Dynamics vol. 26, no. 1, 2000, pp. 43-55.

Pitout, M. Televisie en resepsiestudie: 'n analise van kykersinterpretasie van die seepopera Egoli—plek van goud. Diss. U of South Africa, 1996. http://uir.unisa.ac.za/handle/10500/15793.

Riessman, C. K. “Narrative analysis.” Ed. L. M. Given. The Sage Encyclopaedia of Qualitative Research Methods. Thousand Oaks: Sage, 2008.

SAARF 2014. "SAARF/Marklives \#Top40TVratings: As elections near, news gains." 2 May 2014. http://www. marklives.com/2014/05/saarfmarklives-top40tvratings-elections-near-news-gains/\#.VRz9d_mUfTo. Accessed 11 Nov. 2015.

Shome, R. "Outing whiteness." Review and Criticism vol. 17, no. 3, 2000, pp. 366-71. DOI: https://doi. org/10.1080/15295030009388402.

Sleeter, C. E. “White silence, white solidarity." Race Traitor. Eds. N. Ignatiev and J. Garvey. Routledge, 1996.

Steyn, M. E. "As the postcolonial moment deepens: a response to Green, Sonn, and Matsebula." South African Journal of Psychology vol. 37, no. 3, 2007, pp. 420-24. DOI: https://doi.org/10.1177/008124630703700302. ."The ignorance contract: recollections of apartheid childhoods and the construction of epistemologies of ignorance." Identities: Global Studies in Culture and Power vol. 19, no.1, 2012, pp. 8-25. DOI: https://doi.org/10.1080/1070289X.2012.672840.

Stokes, M. The Color of Sex: Whiteness, Heterosexuality, and the Fictions of White Supremacy. Duke U P, 2001.

Swanepoel, M. “7de Laan: Henry Milne praat padlangs". Rooi Rose January 2015, pp. 35-6.

Twine, F. D. and C. Gallagher. "The future of whiteness: a map of the "Third Wave'". Ethnic and Racial Studies vol. 31, no. 1, 2008, pp. 2-24. DOI: https://doi.org/10.1080/01419870701538836.

Van der Merwe, N. "The appeal of 7de Laan: selected viewer's self-identified reasons for watching." Communicare vol. 31, no.1, 2012, pp. 36-58. http://hdl.handle.net/10520/EJC123805.

Vanhaesebrouck, K. "The hybridization of Flemish identity: the Flemish national heritage on the contemporary stage." Contemporary Theatre Review vol. 20, no. 4, 2012, pp. 465-74. DOI: https://doi.org/1 0.1080/10486801.2010.505760.

Van Zyl and Venter. "SABC wants less Afrikaans in 7de Laan." 25 Aug. 2014. https://www.channel24.co.za/ TV/News/SABC-wants-less-Afrikaans-in-7de-Laan-20140825. Accessed 10 Nov. 2014.

Vice, S. "How do I live in this strange place?" Journal of Social Philosophy vol. 41, no. 3, 2010, pp. 323-42. DOI: https://doi.org/10.1111/j.1467-9833.2010.01496.x.

Yuval-Davis, N. The Politics of Belonging. Intersectional Contestations. London: Sage, 2011. 